\title{
Toxic metal exposure during medication
}

\section{By G. S. FeLl, Department of Biochemistry, Royal Infirmary, Glasgow $G_{4} \circ S F$}

The considerable biological potency of various metallic elements and their compounds has long been of interest to the medical profession. In earlier times large doses of the more toxic metals such as mercury were administered for a variety of reasons, often with serious and even fatal consequences.

The modern pharmacopoeia lists numerous metal compounds which are administered orally, by injection or applied externally. These compounds can be of considerable clinical benefit but are often associated with undesirable side effects. In addition, metals may constitute significant impurities during the manufacture of other pharmaceutical products, requiring close control during manufacture.

When inorganic compounds are administered orally some knowledge of the mechanisms of intestinal absorption, peripheral blood transport, tissue and organ uptake, and of the normal routes of excretion will help the clinician to regulate the actions of these compounds.

Continuing development of modern clinical techniques such as intravenous fluid therapy following surgery or injury, in prolonged intravenous nutrition and longterm renal haemodialysis, has allowed greatly improved patient survival. However, these and related techniques permit the introduction of substances, including metal compounds, directly into the peripheral circulation and thus bypass the important regulatory function exercised by the intestinal mucosa. Accordingly, particular care is required in relation to the dosage of metals given by these routes and monitoring procedures must be used to detect early signs of toxicity.

\section{Metallic compounds used for pharmacological effect}

Examples of this type of drug would include gold sols used in the symptomatic treatment of rheumatoid arthritis, platinum complexes used as cytotoxic drugs, and lithium carbonate used in psychiatric medicine. Each of these drugs is associated with serious toxic side effects. Au therapy was at one time regarded as amongst the most risky of all treatments but careful regulation of dosage, improvements in the methods of administration and an awareness of the potential risk of bone marrow depression and renal damage has now allowed its safer use, with good clinical results (Editorial, 1979).

The $\mathrm{Pt}$ complexes recently introduced as chemotherapeutic agents are proving extremely effective in treatment of certain malignant tumours. However, the drugs are very nephrotoxic and constant checks upon renal function are needed during their use. 
The successful use of oral dosage with $\mathrm{LiCO}_{3}$ has allowed the psychiatrist an important advance in the prophylaxis and treatment of the effective disorders, especially recurrent manic-depression. The dosage given $(1-2 \mathrm{~g})$ is adjusted to maintain blood serum levels between $0.7-1 \cdot 3 \mathrm{mmol} \mathrm{Li} / \mathrm{l}$. Concentrations less than this results in ineffective therapy and a greatly increased relapse rate, whereas concentrations above the upper limit result in increased signs of toxicity. Information as to the patient's renal function, cardiovascular state, and dietary sodium intake is needed before starting therapy and regular clinical examination required to detect impending toxicity. Dosage may have to be reduced or stopped during periods of febrile illness and since therapy may have to be maintained for many years the patient must be instructed to report any undue side effects promptly. Given proper monitoring, $\mathrm{Li}$ therapy has been an effective treatment although the precise mechanism of its action is far from being fully understood (Gershon \& Shopsin, 1973).

\section{Metallic compounds used to correct deficiencies}

Although the widespread supplementation of foodstuffs such us bread with salts of the essential elements calcium and iron may be somewhat controversial in nutritional science, this is not associated with acute toxic effects. However, patients with acute deficiencies of potassium, $\mathrm{Ca}$ and magnesium may be given intravenous injections of the appropriate salts and it is well recognized that strict control of the total dosage and its rate of administration is vital if fatal results are to be avoided. The hazards of intravenous $\mathrm{K}$ therapy are particularly severe and regular checks of renal function, serum $\mathrm{K}^{+}$levels and of cardiovascular status are needed.

The most widespread of all metal deficiency diseases is Fe deficiency anaemia. Treatment by intramuscular injection of Fe-dextran complexes is clinically effective and avoids problems of patient compliance encountered in oral dosage with Fe salts. However, there is a slight but established risk of muscle sarcoma developing at the injection site (Robertson \& Dick, 1977).

The technique of intravenous nutrition has now been developed to a considerable extent and patients can be kept in good nutritional balance for many months, or even years, by means of nutrients such as carbohydrate; fat and amino acids delivered via a central venous catheter (Lee, 1974).

However, for complete intravenous nutrition the regimen must include appropriate amounts of vitamins and all the essential inorganic elements (Shenkin \& Wretlind, 1978). A complex mixture of minerals and trace metals is required (Table I) in various clinical circumstances. Intensive monitoring and metabolic balance studies are desirable if imbalances are to be avoided. At least one fatality has been reported from accidental overdosage with zinc sulphate in such a patient (Brocks et al. 1977). The commercially available trace metal additive mixtures offer a convenient means of supplying at least the basal amounts of a range of essential elements. However, it is certain that these solutions are not ideally 
balanced and not fully appropriate in all types of patient. During trace metal balance studies (G. S. Fell and A. Shenkin, unpublished results), there was some evidence that there is too little $\mathrm{Zn}$ and perhaps too much manganese in at least some preparations. Each patient maintained by intravenous nutrition for any length of time should be studied using modern laboratory methods to allow adjustment of trace metal input. As knowledge of the range of essential elements grows from animal studies, still further elements such as chromium and selenium are advocated for intravenous therapy. Due caution must be exercised until basic knowledge of their metabolic pathways is available and appropriate laboratory means of estimation of $\mathrm{Se}$ and $\mathrm{Cr}$ become widely available.

Table I. Suggested daily supply of minerals for patients on complete intravenous nutrition

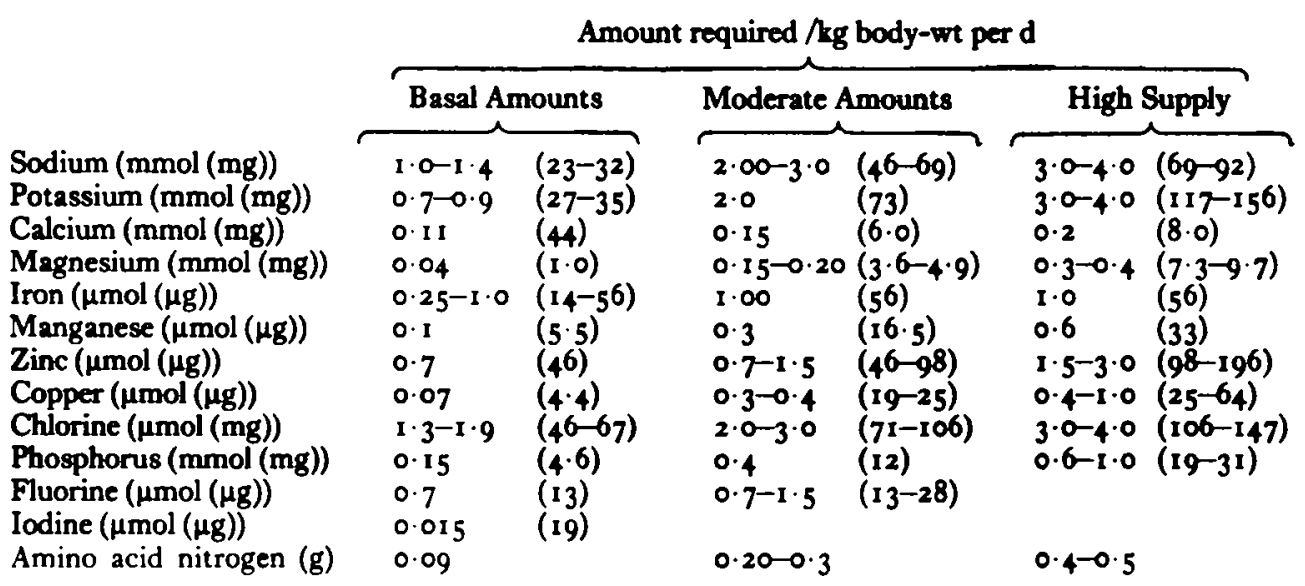

\section{Metal toxicity during renal haemodialysis}

The availability of long-term renal dialysis allows patients, with no recoverable renal function, to be maintained for months or years until a successful renal transplant can be arranged. Various degenerative changes are reported, however, including a refactory anaemia, bone disorders and serious neurological disturbances. Haemodialysis involves the exposure of peripheral blood to dialysis across an artificial membrane against a suitable mixture of salts and nutrients. During this process it is established that as well as the intended removal of urea and other waste products there is a net uptake of a number of trace metals such as copper, $\mathrm{Zn}, \mathrm{Mn}$, aluminium and lead (Stevens et al. 1977). Where accidental contamination of the dialysate occurs with $\mathrm{Cu}$ (Lyle et al. 1976) or $\mathrm{Zn}$ (Gallery et al. 1972) serious haemolytic episodes can occur. Although extensive studies have failed to show obvious effects from the well recognized toxic metals such as 
arsenic, $\mathrm{Pb}$, cadmium or mercury, it has recently been suggested that $\mathrm{Al}$ uptake can cause serious damage.

From epidemiological studies it was established that the geographical distribution of dialysis encephalopathy and metabolic bone disease coincided fairly well with the practice of addition of Al salts to the domestic water supply, which was then used to prepare the dialysis fluids, especially for the 'home dialysis' patients. Water levels of $>300 \mu \mathrm{g} \mathrm{Al} / \mathrm{I}$ appeared to cause significant $\mathrm{Al}$ retention during dialysis. There is a close correlation between serum $\mathrm{Al}$ levels and water $\mathrm{Al}$ concentration (Elliot et al. 1978).

Serum Al concentrations of greater than $300 \mu \mathrm{g} \mathrm{Al} / 1$ are associated with the progressive neurological lesions known as dialysis encephalopathy as well as severe anaemia and osteomalacia. The total body burden of $\mathrm{Al}$ can reach several $\mathrm{g}$ and in addition to $\mathrm{Al}$ in the water supply may arise from accidental contamination of the dialysate and the widespread use of $\mathrm{Al}$ gels given to renal failure patients to regulate intestinal phosphate absorption The biochemical basis of $\mathrm{Al}$ toxicity is not understood but the mechanism of its uptake and tissue distribution appears to be related to similarities between $\mathrm{Al}^{3+}$ and $\mathrm{Ca}^{2+}$ ions. Although only a very small proportion of $\mathrm{Al}^{3+}$ is normally absorbed from the intestine, a positive $\mathrm{Al}$ balance can build up during dosage of the uraemic patient with $\mathrm{Al}(\mathrm{OH})_{3}$. Intestinal absorption of $\mathrm{Al}^{3+}$ is enhanced by the action of parathormone (PTH) in a manner similar to that of $\mathrm{Ca}^{2+}$ (Mayor et al. 1977) and PTH levels are often elevated in chronic renal failure. Once absorbed $\mathrm{Al}^{3+}$ is transported in peripheral blood mainly bound to albumin and taken up mostly by skeletal bone, but muscle liver and kidney will also accumulate the metal. Since, like $\mathrm{Ca}^{2+}$, a significant proportion of $\mathrm{Al}^{3+}(2 \mathrm{O}-30 \%)$ is ionized, it is freely available for excretion in urine in subjects with normal renal function. In patients inadvertently given $\mathrm{Al}^{3+}$ during dialysis the mobile fraction of $\mathrm{Al}^{3+}$ is able to cross the blood-brain barrier, enter the cerebral spinal fluid (CSF) and become deposited in brain tissue. In affected patients there is an elevated CSF Al level, with distribution of $\mathrm{Al}$ mainly in the grey matter (Table 2). Al deposition in bone affects bone mineralization, and its presence in bone marrow may further depress red cell production. The complex effects of $\mathrm{Al}$ in the dialysis patient should be thought of as the Al toxicity syndrome. By application of modern analytical techniques such as carbon furnace atomic absorption with automatic sample injection it is now possible to examine a wide range of other potentially toxic metals in dialysis patients by a reliable yet extremely sensitive technique. There is an increase in serum nickel from a reference range of $2.6 \pm 2.3 \mu \mathrm{g} \mathrm{Ni} / 1(n+9)$ to $14 \cdot 6 \pm 3.7 \mu \mathrm{g} \mathrm{Ni} / 1(n 9)$, in dialysis patients. The clinical significance of this finding is not clear, but the toxic properties of parentally administered $\mathrm{Ni}$ salts in experimental animal studies are well established (Nielsen, 1977). In the case of the trace metal cobalt, there does appear to be a more defined clinical risk associated with high levels of Co accumulated in tissue in dialysis patients. This can arise either from the use of cobaltous chloride to promote red cell production (Manifold et al. 1978) or Co accumulation due to renal failure (Pehrsson \& Lins, 1978). Co toxicity produces a 
cardiomyopathy and high levels of Co were demonstrated by Pehrsson \& Lins (1978) in the heart tissue of uraemic patients. Since the excretion of Co is via the kidney, cobalt therapy would seem contra-indicated in renal failure.

Table 2. Brain tissue aluminium concentrations. • $\mu \mathrm{g} \mathrm{Al} / \mathrm{g}$ dry wt

$\begin{array}{lr}\text { Globus Pallidus } & 3.6 \\ \text { Thalamus } & 8.5 \\ \text { White matter } & 9.6 \\ \text { Putamen } & 11.6 \\ \text { Frontal cortex } & 13.0 \\ \text { Occipital cortex } & 15.0 \\ \text { Panetal cortex } & 16.4\end{array}$

-Samples taken post mortem from a patient with the Al toxicity syndrome.

Metallic compounds as contaminants of pharmaceuticals

As well as controlling the concentrations of the intended product in various preparations, the manufacturer must exclude contamination by a wide range of other metallic elements. Certain metals such as $\mathrm{Hg}$ are used as preservatives and others, $\mathrm{Cu}$ and $\mathrm{Pb}$, may be present as residues from catalysts used in the production of numerous drugs (Rousselet \& Thuillier, 1979). As has been emphasized above, it is particularly important to ensure that products to be given by intravenous injection are free from significant metal contamination. Therefore it was somewhat disturbing to find that the Al content of certain blood plasma products was greater than expected. A survey of plasma albumin solutions sterile plasma protein solution (SPPS), obtained from a variety of sources, revealed a significant increase in $\mathrm{Al}$ concentration, when compared to that found in fresh frozen human plasma (Table 3). Other blood products such as Factor VIII, used in treatment of coagulation disorders, has been found to contain almost $2000 \mu \mathrm{g} \mathrm{Al} / 1$. The $\mathrm{Al}$ and other metals found in these products are inadvertently added during the manufacture of these products and an important source is from impurities in the chemicals required during manufacture.

Table 5. Aluminium content of plasma protein solutions

$\begin{array}{lll} & & \mu \mathrm{g} \mathrm{Al} / 1 \\ \text { Fresh frozen plasma } & 30,28,57 \\ \text { Serum plasma protein solution : Source } \mathrm{I} & 49 \mathrm{I} \pm 159(n 76) \\ & \text { Source 2 } & 660 \\ \text { Source 3 } & 480 \\ \text { Source 4 } & 475 \\ \text { Source } 5 & 275\end{array}$

There is no clear evidence of any toxic effects arising from the use of these products, and large amounts of SPPS are given regularly to a wide variety of patient during plasmapheresis exchange transfusions. It is likely that any excess $\mathrm{Al}$ injected with these proteins is rapidly eliminated in urine by patients with normal renal function. 
Nevertheless, the potential toxicity of $\mathrm{Al}$ and other metals is clearly established and pharmaceutical manufacturers may be advised to improve their quality control procedures to include a wider range of metal analysis, at lower detection limits, than presently practised.

\section{Conclusions}

It is certain that much clinical advantage can be obtained from the proper use of the growing range of inorganic drugs. Strict control of dosage and special care taken when intravenous injection is required, can do much to reduce toxicity. Unsuspected effects arising from the accidental administration of excessive amounts of various metals present as contaminants should be avoided by improvements in manufacturing practice and clinical awareness of potential risks.

\section{REFERENCES}

Brooks, A., Reid, H. \& Glazer, G. (1977). Br. med. f. 1, 1390.

Editorial, (1979). Br. med. F. I, 289.

Elliot, H. L., Dryborgh, F., Fell, G. S., Sabet, S. \& MacDougall, A. I. (1978). Br. med. J. I, I101. Gallery, E. D., Blomfield, J. \& Dixon, S. R. (1972). Br. med. f. 4, 331 .

Gershon. S. \& Shopsin, B. (1973). [editors]. Lithium, its role in psychiatric research and treatment. New York and London: Plenum Press.

Lee, H. A., (1974). [editor]. Parenteral nutrition in acute metabolic illness. London and New York: Academic Press.

Lyle, W. H., Payton, J. E. \& Hui, M. (1976). Lancet ii, 1324.

Manifold, I. H., Platts, M. M. \& Kennedy, A. (1978). Lancet ii, r6og.

Mayor, G. H., Makdani, D. D. \& Keiser, J. A. (1977). In Toxicology of Trace Elements, p.4I, [R. A. Goyer and M. A. Mehlman, editors]. Washington and London: Hemisphere Publishing Corp.

Neilsen, F. H. (1977). In Toxicology of Trace Elements, p. I32 [R. A. Goyer and M. A. Mehiman, editors]. Washington and London: Hemisphere Publishing Corp.

Pehrsson, A. \& Lins, L. E. (1978). Lancet ii, 51.

Robertson, A. G. \& Dick, W. C. (1977). Br. med. J. 1, 946.

Rousselet, F. \& Thuillier, F. (1979). Prog. analyt atom. spectroc. 1, 353.

Shenkin, A. \& Wretland, A. (1978). Wld Rev. Nut. Diet. 28, I. 